\title{
Evaluation of Outcome of Timing of Surgical Intervention on Cauda Equina Syndrome
}

\section{Rajesh Pratap Shah, Bishnu Babu Thapa, Sushil Rana Magar, Ritesh Sinha, Pankaj Chand, Dipendra Maharjan, Sushil Shrestha and Rabi Bhandari}

Department of Orthopaedics, Nepalese Army Institute of Health Sciences, Shree Birendra Hospital, Chhauni, Kathmandu, Nepal

\begin{abstract}
Introduction: Cauda equina syndrome (CES) is a rare clinical entity caused by compression of lumbar and sacral nerve roots resulting in various neurological dysfunctions. Early diagnosis of the syndrome and timely intervention is required to prevent permanent disability.

Methods: This is a retrospective study conducted from January 2013 to December 2017 in a tertiary care centre in Kathmandu, Nepal. All the cases meeting the inclusion criteria were included in the study. Patients were operated using posterior open discectomy and the outcome was evaluated at two weeks , one month, three months, six months and one year.

Result: Total number of patients meeting the inclusion criteria was 10, two females and eight males with a mean age of $40.30 \pm 6.58$ years. The mean time for onset of symptom to timing of surgery was $142 \mathrm{hrs}$. VAS for leg improved from $5.90 \pm 0.738$ to $0.70 \pm 0.483$ and VAS for back pain improved from $3.20 \pm$ 1.476 to $0.5 \pm 0.572$ post operatively. There was improvement in sensory and motor function in all the cases. Bowel and bladder function improved in all the cases postoperatively at the time of final follow up. Sexual function was impaired in six patients preoperatively but postoperatively four had improved and two patients had poor result at the time of final follow up.

Conclusions: Timing of surgery may not be the most important determining factor for the outcome of the CES. Surgical decompression in delayed presentation have good clinical outcome in CES.

Key words: Back pain; Cauda Equina Syndrome; Disability; VAS
\end{abstract}

Correspondence: Rajesh Pratap Shah, Department of Orthopaedics, Nepalese Army Institute of Health Sciences, Shree Birendra Hospital, Chhauni, Kathmandu, Nepal. E-mail: roam2rajesh@gmail.com

DOI: $10.3126 / \mathrm{mjsbh} . v 20 \mathrm{i} 1.26686$

Submitted on: 2019-12-09

Accepted on: 2020-03-10 


\section{INTRODUCTION}

Cauda Equina syndrome (CES) is a rare and serious clinical manifestation of lumbar and sacral nerve roots caused due to compression of conus medullaris. ${ }^{1,2}$ There are various causes for compression of nerve roots amongst them lumbar disc herniation (LDH) is the commonest. ${ }^{3-5}$ Presenting symptoms may be back ache, unilateral or bilateral radiating leg pain, sensory or motor impairment, absent Achille's tendon reflex, loss of perianal sensation and sphincter dysfunction which may result in permanent disability if left untreated. ${ }^{6-8}$

In spite of various causes of cauda equina syndrome, removal of the compression by surgical decompression is the only treatment of choice. However, the role of timing to surgery for decompression as a prediction for prognostic factor is controversial. Various authors have supported early intervention as a better outcome ${ }^{9-12}$ while others have found no correlation between timing of surgery and its outcomes. ${ }^{13-15}$

This study was done to find out the influence of timing from onset of symptom to surgery and to evaluate the outcome of improvement in symptoms after the surgery.

\section{METHODS}

This is a retrospective study conducted in Shree Birendra Hospital, Chhauni, Kathmandu, Nepal from January 2013 to December 2017. Ethical Clearance was taken from Institution Review Committee. The data of patients were collected from the medical record books from the record department. The patients diagnosed as CES from history, clinical investigations and positive MRI findings were included in the study. The exclusion criteria were patients with previous history of any kind of spine surgery and the patients who did not give consent. The variables such as age, sex,

Table 1. level of lesion

\begin{tabular}{|l|r|r|}
\hline Level & No & \multicolumn{2}{|c}{ Percentage } \\
\hline L3 - L4 & 1 & 10 \\
\hline L4 - L5 & 5 & 50 \\
\hline L5 - S1 & 4 & 40 \\
\hline
\end{tabular}

clinical symptoms, topographic compression level, duration of symptoms, time from onset of symptoms to definitive treatment and duration of reversal of symptoms after definitive treatment were studied. All the cases were operated under general anaesthesia using posterior open discectomy. No posterior instrumentation was done as all the cases had bilateral partial facetectomy. Postoperatively, patients were allowed to ambulate as pain tolerated. The dressing was done on fourth postoperative day and stitches were removed on 14th postoperative day. The clinical outcome was studied at two weeks, one month, three months, six months and one year. The data was analysed using SPSS version 21. The study was approved by ethical committee of our institute.

\section{RESULTS}

Sample size meeting the inclusion criteria was 10 $(n=10)$, out of which there were eight males and two females with mean age of $40.30+/-6.58$ years. All the cases in our study had lumbar disc herneation with L4 - L5 disc being the most frequently involved followed by L5 - S1 and there was only one case with LDH of L3 - L4 (Table 1).

The mean time for onset of symptom to timing of surgery was 142 hours with only two cases being operated within 48 hours. (Table 2). Similarly preoperative Visual Analogue Scale (VAS) for leg pain was $5.90 \pm 0.738$ which improved to $0.70 \pm 0.483$ and VAS for back pain improved from $3.20 \pm 1.476$ to $0.5 \pm 0.572$ at the time of final follow up (Table $3)$.

After the decompression there was improvement in sensory and motor function in all patients. The bowel and bladder function were impaired in all the patients and all of them showed improvement postoperatively at the time of final follow up. Sexual function was impaired in six patients amongst them four had improvement and two

Table 2. Time to onset of symptom

\begin{tabular}{l|r|r}
\hline Time & No of patients & \multicolumn{2}{|c}{ Percentage } \\
\hline$<48 \mathrm{hrs}$ & 2 & 20 \\
\hline$>48 \mathrm{hrs}$ & 8 & 80 \\
\hline
\end{tabular}


Table 3. Per-op and post-op VAS

\begin{tabular}{|l|l|l|}
\hline \multicolumn{1}{|l|}{ Symptoms } & Pre & Post op \\
\hline Leg pain & $5.90+/-0.738$ & $0.70+/-0.483$ \\
\hline Back pain & $3.20+/-1.476$ & $0.5+/-0.572$ \\
\hline
\end{tabular}

patients had poor result at the time of final follow up.

\section{DISCUSSION}

CES is caused by compression on cauda equina which results in severe neurological impairment along with bowel and bladder dysfunction. It is a rare clinical syndrome and may result in permanent disability if left untreated.6,8 Compression to lumbosacral nerve roots can be due to degenerative, infective, inflammatory, neoplastic and traumatic causes. Among them LDH is the most common cause in developing countries. ${ }^{4,5,16}$ All the case of cauda equina syndrome in our study were caused by lumbar disc herniation. The mean age of patients was $40.30+/-6.58$ years which is similar to the findings of various authors. Male patients were predominant in this study. This could be because of small sample size and lumbar disc herniation being the only cause for CES in this study. The compression level resulting in CES was L4 - L5 being the most common followed by L5 - S1 and L3 - L4 which were similar in the study done by Fuso and Shapiro et al. ${ }^{1,17}$ The patient diagnosed with CES had herniated disc occupying more than $50 \%$ of the spinal canal causing compression to the nerve roots in our study. In a developmentally narrow canal, even a prolapsed of one third of disc can lead to CES. ${ }^{18}$

Out of 10 only two cases were operated within 48 hours. The mean time for patient to receive definitive surgery after the development of symptom was 142 hours ranging from 1.5 day to 14 days. There was delay of $11+/-24$ days in study conducted by Fernando and delay of 1 to 14 days in the study done by Jason Busse. ${ }^{1,19}$ All the patients of cauda equina syndrome, presented in our hospital were operated within 24 hours of presentation.

The delay in presentation could be because of ignorance and lack of knowledge. In periphery many patients receive treatment for low back ache and manage conservatively for long time period and present to hospital only if the symptoms gets worsen. Further delay could be because of lack of diagnostic tool and prompt referral system. The health care centre of periphery has limited diagnostic resources, more over the low socioeconomic conditions of several patients could be the reason for delay in receiving medical assistance. More over the terrain of the country and inaccessibility to centre for the appropriate treatment makes it delayed further.

The VAS score for leg pain and back pain improved significantly after the posterior mid line decompression during 2nd and 3rd follow up. Similarly, there was improvement in the sensory and motor function after the surgery in all the patients which was similar to the other studies. ${ }^{16,17,20}$ There were three patients with MRC grade 4 who had improved immediately after the surgery. Three patients with MRC grade 3 had delayed recovery. Patients with longer duration of symptoms were the one in delayed recovery. However all the patient recovered by final follow up with physiotherapy management.

The bladder function was impaired in all the patients at the time of presentation. The bladder function impairment were dribbling of urine, retention and overflow incontinence. Some patients presented with impairment of perianal sensation, altered urinary sensation, difficult or strain to void urine or a combination of these symptoms. ${ }^{4}$ Postoperatively all the patients showed improvement in bladder function after physiotherapy during the final follow up. Eight patients out of 10 were operated after $48 \mathrm{hrs}$ and all the patients had improvement in their bladder function. This indicate that there is no significant role of urgent decompression in terms of functional outcome for involvement of bladder function. ${ }^{10,21-23}$ Sexual dysfunction was not mentioned pre operatively but was reported in subsequent follow up. There were six $(60 \%)$ patients who had sexual dysfunction. Amongst them four patient showed improvement while two patients had poor result at final follow up. The sexual dysfunction was evaluated by questionnaire basis like impotence, erection problem, difficult to obtain orgasm, altered penile or vaginal sensation and incontinence during 
inter course. ${ }^{24}$ There was problem while questioning about the sexual dysfunction because of cultural barrier. It has not been mentioned adequately in literature regarding sexual dysfunction.

\section{CONCLUSIONS}

Though the outcome of CES decompressed within $48 \mathrm{hrs}$ is good, patients with LDH induced CES with delayed presentation can also have good clinical improvements after decompression. The evidence from this study suggests that timing from onset of symptoms to surgical decompression may not only be the most important determining factor.
The length of justifiable delay is not known in CES. However large number of sample size and long term follow up is still required to set up a guide line to decide the time frame for intervention in CES.

To cite this article: Shah RP, Thapa BB, Magar SR, Sinha R, Chand P, Maharjan D, et al. Evaluation of Outcome of Timing of Surgical Intervention on Cauda Equina Syndrome,. MJSBH. 2021;20(1):19-23.

Conflict of Interest: None declared

\section{REFERENCES}

1. Fuso FAF, Dias ALN, Letaif OB, Cristante AF, Marcon RM, de Barros TEP. Epidemiological study of cauda equina syndrome. Acta Ortop Bras. 2013;21(3):159-62. DOI: 10.1590/S1413-78522013000300006.

2. McNamee J, Flynn P, O'Leary S, Love M, Kelly B. Imaging in cauda equina syndrome--a pictorial review. Ulster Med J. 2013;82(2):100-8. PMID: 24082289

3. Korse N, Pijpers J, Van Zwet E, Elzevier H, Vleggeert-Lankamp C. Cauda Equina Syndrome: presentation, outcome, and predictors with focus on micturition, defecation, and sexual dysfunction. Eur Spine J. 2017;26(3): 894-904. DOI: 10.1007/s00586-017-4943-8.

4. Fraser S, Roberts L, Murphy E. Cauda equina syndrome: a literature review of its definition and clinical presentation. Arch Phys Med Rehabil. 2009;90(11):1964-8. DOI: 10.1016/j.apmr.2009.03.021.

5. Dhatt SS. Outcome of Spinal Decompression in Cauda Equina Syndrome Presenting Late in Developing Countries: Case Series of 50 Cases. Spine J. 2015;15(10):S90-S1. DOI: 10.1007/s00586-011-1840-4.

6. Sherphard R. Diagnosis and prognosis of cauda equina syndrome produced by protrusion of lumbar disk. Br Med J. 1959;2:434. DOI: $10.1136 / \mathrm{bmj} .2 .5164 .1434$

7. Shapiro S. Cauda equina syndrome secondary to lumbar disc herniation. Neurosurgery. 1993;32(5):743-7. DOI: 10.1227/00006123-199305000-00007

8. Adam D, Hornea I. Cauda equina syndrome secondary to lumbar disc herniation. Report of three cases. Romanian Neurosurgery. 2013;20(3):261-6. DOI: 10.2478/romneu-2013-0009

9. Todd N. Cauda equina syndrome: the timing of surgery probably does influence outcome. Br J Neurosurg. 2005;19(4):301-6. DOI: 10.1080/02688690500305324

10. Qureshi A, Sell P. Cauda equina syndrome treated by surgical decompression: the influence of timing on surgical outcome. Eur Spine J. 2007;16(12):2143-51. DOI: 10.1007/s00586-007-0491-y

11. Ahn UM, Ahn NU, Buchowski JM, Garrett ES, Sieber AN, Kostuik JP. Cauda equina syndrome secondary to lumbar disc herniation: a meta-analysis of surgical outcomes. Spine. 2000;25(12):1515-22. DOI: 10.1097/00007632-200006150-00010

12. Delong WB, Polissar N, Neradilek B. Timing of surgery in cauda equina syndrome with urinary retention: metaanalysis of observational studies. J Neurosurg. 2008;8(4):305-20. DOI: 10.3171/SPI/2008/8/4/305. 
13. Bydon M, Lin JA, De la Garza-Ramos R, Macki M, Kosztowski T, Sciubba DM, et al. Time to surgery and outcomes in cauda equina syndrome: an analysis of 45 cases. World neurosurg. 2016;87:110-5. DOI: 10.1016/ j.wneu.2015.12.054.

14. Chau AMT, Xu LL, Pelzer NR, Gragnaniello C. Timing of surgical intervention in cauda equina syndrome: a systematic critical review. World neurosurg. 2014;81(3-4):640-50. DOI: 10.1016/j.wneu.2013.11.007.

15. Germon T, Ahuja S, Casey AT, Todd NV, Rai A. British Association of Spine Surgeons standards of care for cauda equina syndrome. Spine J. 2015;15(3):S2-S4. DOI: 10.1016/j.spinee.2015.01.006.

16. Kapetanakis S, Chaniotakis C, Kazakos C, Papathanasiou JV. Cauda equina syndrome due to lumbar disc herniation: a review of literature. Folia medica. 2017;59(4):377-86. DOI: 10.1515/folmed-2017-0038

17. Shapiro S. Medical realities of cauda equina syndrome secondary to lumbar disc herniation. Spine. 2000;25(3): 348-52. DOI: 10.1097/00007632-200002010-00015

18. Choudhury A, Taylor J. Cauda equina syndrome in lumbar disc disease. Acta Orthopaedica Scandinavica. 1980;51(1-6):493-9. DOI: 10.3109/17453678008990830

19. Busse JW, Bhandari M, Schnittker JB, Reddy K, Dunlop RB. Delayed presentation of cauda equina syndrome secondary to lumbar disc herniation: functional outcomes and health-related quality of life. CJEM. 2001;3(4): 285-91. DOI: $10.1017 / \mathrm{s} 1481803500005789$

20. Kleinstueck F, Fekete T, Jeszenszky D, Mannion A, Grob D, Lattig F, et al. The outcome of decompression surgery for lumbar herniated disc is influenced by the level of concomitant preoperative low back pain. Eur Spine J. 2011;20(7):1166-73. DOI: 10.1007/s00586-010-1670-9.

21. Gleave JR, Macfarlane R. Prognosis for recovery of bladder function following lumbar central disc prolapse. Br J neurosurg. 1990;4(3):205-9. DOI: 10.3109/02688699008992725

22. Jennett WB. A study of 25 cases of compression of the cauda equina by prolapsed intervertebral discs. JJNNP.. 1956;19(2):109. DOI: 10.1136/jnnp.19.2.109

23. Gleave J, Macfarlane R. Cauda equina syndrome: what is the relationship between timing of surgery and outcome? Br J neurosurg. 2002;16(4):325-8. DOI: 10.1080/0268869021000032887

24. Korse N, Jacobs W, Elzevier H, Vleggeert-Lankamp C. Complaints of micturition, defecation and sexual function in cauda equina syndrome due to lumbar disk herniation: a systematic review. Eur Spine J. 2013;22(5):1019-29. DOI: 10.1007/s00586-012-2601-8. 